\title{
BMJ Open Oral health of high-cost patients and evaluation of oral health measures as predictors for high-cost patients in South Korea: a population-based cohort study
}

Yeonkook Joseph Kim

To cite: Kim YJ. Oral health of high-cost patients and evaluation of oral health measures as predictors for high-cost patients in South Korea: a population-based cohort study. BMJ Open 2019:9:e032446. doi:10.1136 bmjopen-2019-032446

- Prepublication history and additional material for this paper are available online. To view these files, please visit the journal online (http://dx.doi org/10.1136/bmjopen-2019032446).

Received 19 June 2019 Revised 06 August 2019 Accepted 13 August 2019

D Check for updates

(C) Author(s) (or their employer(s)) 2019. Re-use permitted under CC BY-NC. No commercial re-use. See rights and permissions. Published by BMJ.

College of Business, Chungbuk National University, Cheongju, Republic of Korea

Correspondence to Dr Yeonkook Joseph Kim; yjk15@snu.ac.kr

\section{ABSTRACT}

Objective To examine the oral health conditions and oral health behaviour of high-cost patients and evaluate oral health measures as predictors of future high-cost patients. Design A retrospective, population-based cohort study using administrative healthcare records.

Setting The National Health Insurance Service (NHIS) medical check-up database (a.k.a. NHIS — national health screening cohort database) in South Korea.

Participants 131549 individuals who received biennial health check-ups including dental check-ups in 2011 or 2012, aged 49-88.

Primary outcome measures Current and subsequent year high-cost patient status.

Results High-cost patients, on average, incur higher dental costs, suffer more from periodontal disease, brush their teeth less and use secondary oral hygiene products less. Some of the self-reported oral health behaviours and oral symptom variables show statistically significant associations with subsequent year high-cost patient indicators, even after adjusting for demographic, socioeconomic, medical conditions, and prior healthcare cost and utilisation.

Conclusions We demonstrate that oral health measures are associated with an increased risk of becoming a highcost patient.

\section{INTRODUCTION}

Studies have shown that a small portion of the population uses the majority of healthcare resources, highlighting the importance of predicting high-cost patients by recognising the characteristics and patterns of their healthcare utilisation for targeted interventions and for the modelling of patient risk factors for more equitable healthcare reimbursements. ${ }^{1}$ If certain patient characteristics are predictive of highly persistent use, it may be possible to offer more cost-effective alternatives to frequent primary care visits, including disease management, case management, group visits and patient education. ${ }^{2}$ Wammes et al conducted an extensive
Strengths and limitations of this study

- This is the first study to provide empirical evidence of the oral health characteristics of high-cost patients.

- This study is conducted using a large-scale health check-up cohort database.

- We compare current patient characteristics and oral health conditions of high-cost patients with those of the non-high-cost group.

- We evaluate six oral health measures as predictors for the following year high-cost patient status using multivariate logistic regression models.

- This study is limited by 1 -year prediction period (ie, we predict the outcome in 2012 using the data from 2011 and we predict the outcome in 2013 using the data from 2012).

systematic review of the characteristics and healthcare utilisation of high-cost patients. ${ }^{3}$ However, to the best of our knowledge, the oral health characteristics of high-cost patients have not been studied.

Poor oral health has been shown to be associated with increased risk of various diseases and mortality. ${ }^{4-7}$ For example, studies show associations between periodontal disease and a higher risk of Alzheimer's disease, coronary heart disease, rheumatoid arthritis, glomerulonephritis, inflammatory bowel disease and prostate cancer. ${ }^{8-10}$ Other studies show that poor oral hygiene is associated with hypertension, diabetes mellitus, cardiovascular disease, and head and neck cancers. ${ }^{11-14}$ Still other studies have found a positive association between poor oral health and mortality. ${ }^{415}$

Given that poor oral health is associated with many of chronic and severe diseases, we conjecture that high-cost patients have poor oral health. To test this hypothesis, using a large-scale health check-up database in Korea, we analyse the oral health of high-cost 
patients. One main reason to study the characteristics of high-cost patients is to predict future high-cost patients for targeted interventions. We evaluate oral health measures as predictors in the high-cost patient predictions. In short, our objective is to examine the oral health conditions and oral health behaviours of current highcost patients and to evaluate which oral health measures identify future high-cost patients.

\section{MATERIALS AND METHODS \\ Participants and setting}

We analyse the National Health Insurance Service (NHIS) medical check-up database (also known as the NHISnational health screening cohort (NHIS-HEALS)) of Korea. ${ }^{16}$ The NHIS is a uniform insurance policy administrator that covers all residents of Korea. The NHIS datasets represent the entire population in Korea. Therefore, this database is a suitable source of information for nationwide population-based studies. ${ }^{17}$

To construct the NHIS-HEALS database, a sample cohort was first selected from the 2002 and 2003 health screening participants (aged between 40 and 79 in 2002) and followed up through $2013 .{ }^{16}$ In 2002, this cohort has 514866 health check-up participant, which is a $10 \%$ random sample of the total number of health check-up participants in 2002 and 2003. The NHIS-HEALS database consists of four databases: an eligibility database, a medical check-up database, a claims database and a healthcare provider database. To use the most recent data in the database, we construct the study database with a medical check-up data set that contains information on examinees who received biennial medical and dental check-ups in 2011 or 2012.

The medical check-up data are generated through the National Health Screening Program (NHSP), which is a free national medical check-up programme for NHIS beneficiaries who are 40 or older. $^{18}$ NHIS enrollees eligible for the NHSP are required to have a medical check-up biennially. The NHSP consists of a set of laboratory tests, a dental examination and questionnaires on self-reported health behaviour. Our study sample consists of 131549 enrollees who participated in the NHSP in 2011 or 2012 aged from 49 to 88 . For those enrollees who participated in both years, we only use 2011 observation to avoid duplication. ${ }^{18}$ Since the majority of high cost patients are 50 years and older in Korea and many other countries, we use a large sample of that population segment in this study. ${ }^{1319}$ Using a join key in the database, we extract their claims and eligibility information from the claims and eligibility datasets, respectively, and merge them with the medical check-up information. (For more information on how to use the database, please visit the NHIS website: nhiss.nhis.or.kr.)

\section{Patient involvement}

A de-identified population healthcare data are used in this study. Thus, patients were not involved in the development of the research question, the outcome measures or the study design.

\section{Statistical methods}

\section{Variables}

Following prior studies, we define a 'high-cost' patient as an individual in a sample who is in the upper decile of annual healthcare expenditures. ${ }^{13}$ We create a binary indictor for high-cost patients using all of the data in the database. For example, the medical check-up database contains 487835 enrollees in 2011, and we tag enrollees who are in the upper decile of annual healthcare expenditures as high-cost patients. See online supplementary file 1 for further details.

To understand the oral health conditions of high cost patients, we compare the characteristics and health behaviour of these patients with those of a non-high-cost group. We compare demographic factors (gender and age), socioeconomic (income level) information, healthcare expenditures and the total inpatient length of stay (LOS) as a measure of healthcare utilisation.

We examine the three lifestyle risk factors of body mass index (BMI), pack-years smoked and physical activity, all of which are associated with future healthcare expenditures. ${ }^{20}$ Pack-years smoked values are calculated by multiplying the number of packs of cigarettes smoked per day by the number of years the person has smoked. The physical activity measure is from a questionnaire asking about the number of days a check-up participant exercises at a moderate level for more than $30 \mathrm{~min}$ in activities such as fast walking, playing tennis and riding a bicycle.

Prior studies point to a high prevalence of multiple chronic conditions to explain high-cost patients' high utilisation rates. ${ }^{3}$ We examine the chronic conditions of high-cost patients. Disease information in our claims dataset is coded based on the International Classification of Diseases-Tenth Revision (ICD-10) coding scheme.

We select six oral health measures from the claims data, the dental check-up and questionnaire data in the database based on findings from prior studies (first three variables) and on the statistical significance of the association with high-cost patient status (next three variables). The first three variables are the prevalence of periodontal diseases, the frequency of toothbrushing, and the use of floss or interdental brushes. The last three are self-reported oral symptoms: tongue or inside-cheek pain (yes/ no), difficulty in enunciation due to teeth/denture/gum conditions (yes, slightly, or no) and difficulty in chewing food due to teeth/denture/gum conditions (yes/no). We exclude participants with missing data for age $(n=0$; $0 \%)$, BMI $(\mathrm{n}=3184 ; 2.42 \%)$, pack-years smoked $(\mathrm{n}=3749$; $2.85 \%)$, physical activity $(\mathrm{n}=3336 ; 2.54 \%)$, toothbrushing frequency $(n=1305 ; 0.99 \%)$, use of floss/interdental brushes $(\mathrm{n}=554 ; 0.42 \%)$, tongue or inside-cheek pain $(\mathrm{n}=472 ; 0.36 \%)$, difficulty in enunciation $(\mathrm{n}=4042$; $3.07 \%)$ and difficulty in chewing food $(n=3511 ; 2.67 \%)$ from the corresponding analyses. 


\section{Statistical analyses}

We conduct a $\chi^{2}$ test and a t-test to compare the characteristics and health behaviours of the high-cost patient group with those of the non-high-cost group in years 2011 and 202. Because healthcare expenditure variables exhibit marked positive skewness, with a few high-cost patients and many low-expenditure or zero-expenditure healthcare users, we perform both a t-test and a Wilcoxon rank sum test.

To evaluate oral health measures as predictors of highcost patients, we measure the associations between oral health measures and future high-cost patient status (ie, a binary indictor of high-cost patient status in the subsequent year) using multivariate logistic regression models. We predict the outcome in 2012 using the data from 2011, and we predict the outcome in 2013 using the data from 2012. We select covariates in our models based on prior high-cost patient and healthcare cost prediction studies. ${ }^{120-22}$ We develop four different models. The first model adjusts for three confounders: age, gender and income. For the second model, we add the three lifestyle risk factors of BMI, pack-years smoked and physical activity. For the third model, we adjust for chronic conditions. Wammes et al point to a high prevalence of multiple (chronic) conditions to explain high-cost patients' utilisation. ${ }^{3}$ We add 46 major chronic disease indicators selected in van den Bussche to the first model.$^{23}$ Since some of these chronic disease indicators show high associations, we use the stepwise feature-selection procedure in SAS V.9.4 to eliminate insignificant and collinear variables. For the last model, we add prior healthcare cost and LOS.

\section{RESULTS}

The general characteristics of the high-cost patients are presented in table 1 . The percentage of high-cost patients in our sample is $6.52 \%$, as people who go to health check-ups tend to be younger and less likely to be highcost patients. Consistent with prior studies, high costs are associated with increasing age. ${ }^{3}$ The mean age for the non-high-cost group is 58, whereas the mean for the highcost patient group is 64 in our sample data. As income increases, the likelihood of becoming a high-cost patient decreases. Enrollees in medical aid programme do not report income, and a much higher proportion of high-cost patients are in medical aid programme compared with those in the non-high-cost group ( $1.5 \%$ vs $0.24 \%)$. About $7.35 \%$ of total high-cost patients are in the lowest income decile, whereas $6.45 \%$ of the non-high-cost group are in the same decile. On the other hand, 22.25\% of total highcost patients are in the highest income decile, whereas $24.32 \%$ of the non-high-cost group are in the same decile. The average total cost for the high-cost patient group in 2011 is $\$ 6608$, almost eight times higher than that for the non-high-cost group. The total average drug cost for high-cost patients is about 3.8 times higher than that for the non-high-cost group as of 2011. High-cost patients also incurred 1.4 times more, on average, in dental costs
Table 1 Current high-cost patient characteristics (from years 2011 to 2012 )

\begin{tabular}{|llll}
\hline Patient characteristics & $\begin{array}{l}\text { Non high } \\
\text { cost }\end{array}$ & High cost & P value* $^{*}$ \\
\hline N & 122974 & 8575 & \\
$\%$ & $93.48 \%$ & $6.52 \%$ & \\
\% female & $40.80 \%$ & $47.60 \%$ & \\
\hline Age (years) & $58.45 \pm 0.02$ & $63.83 \pm 0.09$ & $<0.0001$ \\
\hline Income decile (\%) & & & $<0.0001$ \\
\hline Medical aid & $0.24(0.01)$ & $1.5(0.13)$ & \\
\hline 1 & $6.45(0.07)$ & $7.35(0.28)$ & \\
\hline $2-5$ & $24.61(0.12)$ & $23.25(0.46)$ & \\
$6-9$ & $44.39(0.14)$ & $45.64(0.54)$ & \\
10 & $24.32(0.12)$ & $22.25(0.45)$ & \\
\hline
\end{tabular}

Total cost (TC) (\$)

$\begin{array}{llll}\text { Avg. TC } 2011 & \$ 858 \pm 3 & \$ 6608 \pm 80 & <0.0001 \\ \text { Avg. TC } 2012 & \$ 936 \pm 4 & \$ 7043 \pm 90 & <0.0001 \\ \text { Avg. RX cost } 2011 & \$ 353 \pm 2 & \$ 1342 \pm 22 & <0.0001 \\ \text { Avg. RX cost } 2012 & \$ 367 \pm 2 & \$ 1255 \pm 26 & <0.0001 \\ \text { Avg. Dental cost } 2011 & \$ 44 \pm 0 & \$ 63 \pm 4 & <0.0001 \\ \text { Avg. Dental cost } 2012 & \$ 48 \pm 0 & \$ 70 \pm 3 & <0.0001\end{array}$

Healthcare Utilisation

Total inpatient length of $0.59(0.01) \quad 16.31(0.30)<0.0001$ stay (days)

Lifestyle risk factors

\begin{tabular}{llll} 
BMI $\left(\mathrm{kg} / \mathrm{m}^{2}\right)$ & $24.02 \pm 0.01$ & $24.32 \pm 0.03$ & $<0.0001$ \\
\hline Pack-years smoked & $7.82 \pm 0.04$ & $8.31 \pm 0.17$ & $<0.0001$ \\
$\begin{array}{l}\text { Physical activity (days/ } \\
\begin{array}{l}\text { week) } \\
\text { Phe }\end{array}\end{array}$ & $1.47 \pm 0.01$ & $1.34 \pm 0.02$ & $<0.0001$
\end{tabular}

\section{Chronic conditions}

\begin{tabular}{|c|c|c|c|}
\hline Chronic condition count & $2.26 \pm 0.01$ & $4.87 \pm 0.03$ & $<0.0001$ \\
\hline $\begin{array}{l}\text { Chronic low back pain } \\
(\%)\end{array}$ & $33.32(0.13)$ & $58.93(0.53)$ & $<0.0001$ \\
\hline Hypertension (\%) & $25.75(0.12)$ & $38.55(0.53)$ & $<0.0001$ \\
\hline Osteoarthrosis (\%) & $15.92(0.1)$ & $37.14(0.52)$ & $<0.0001$ \\
\hline $\begin{array}{l}\text { Severe vision reduction } \\
(\%)\end{array}$ & $11.22(0.09)$ & $30.95(0.5)$ & $<0.0001$ \\
\hline $\begin{array}{l}\text { Lipid metabolism } \\
\text { disorders (\%) }\end{array}$ & $8.06(0.08)$ & $10.78(0.33)$ & $<0.0001$ \\
\hline Prostatic hyperplasia (\%) & $6.07(0.07)$ & $15.88(0.39)$ & $<0.0001$ \\
\hline Thyroid dysfunction (\%) & $4.58(0.06)$ & $8.06(0.29)$ & $<0.0001$ \\
\hline Neuropathies (\%) & $3.9(0.06)$ & $11.11(0.34)$ & $<0.0001$ \\
\hline Cancers (\%) & $3.03(0.05)$ & $22.04(0.45)$ & $<0.0001$ \\
\hline $\begin{array}{l}\text { Chronic ischaemic heart } \\
\text { disease (\%) }\end{array}$ & $3.23(0.05)$ & $15.16(0.39)$ & $<0.0001$ \\
\hline $\begin{array}{l}\text { Cerebral ischaemia/ } \\
\text { Chronic (\%) }\end{array}$ & $2.14(0.04)$ & $11.69(0.35)$ & $<0.0001$ \\
\hline Haemorrhoids (\%) & $2.25(0.04)$ & $4.01(0.21)$ & $<0.0001$ \\
\hline Depression (\%) & $1.45(0.03)$ & $6.05(0.26)$ & $<0.0001$ \\
\hline Severe hearing loss (\%) & $1.34(0.03)$ & $2.92(0.18)$ & $<0.0001$ \\
\hline $\begin{array}{l}\text { Rheumatoid arthritis/ } \\
\text { Chronic (\%) }\end{array}$ & $1.22(0.03)$ & $3.84(0.21)$ & $<0.0001$ \\
\hline
\end{tabular}

Continued 


\begin{tabular}{|llll|}
\hline Table 1 Continued & & & \\
\hline Patient characteristics & $\begin{array}{l}\text { Non high } \\
\text { cost }\end{array}$ & High cost & P value $^{*}$ \\
\hline $\begin{array}{l}\text { Cardiac arrhythmias (\%) } \\
\text { Somatoform disorders }\end{array}$ & $0.82(0.09)$ & $3.36(0.19)$ & $<0.0001$ \\
$\begin{array}{l}\text { (\%) } \\
\text { Dementia (\%) }\end{array}$ & $0.45(0.02)$ & $2.93(0.18)$ & $<0.0001$ \\
Renal insufficiency (\%) & $0.28(0.02)$ & $3.1(0.19)$ & $<0.0001$ \\
Cardiac insufficiency (\%) & $0.28(0.02)$ & $1.59(0.13)$ & $<0.0001$ \\
\hline Parkinson's disease (\%) & $0.17(0.01)$ & $1.82(0.14)$ & $<0.0001$ \\
\hline
\end{tabular}

Values are presented as mean \pm SE or percentages with $S E$ in parentheses.

${ }^{*} P$ values are obtained by $\chi^{2}$ test/t-test/Wilcoxon rank sum test. BMI, body mass index.

compared with the non-high-cost group. With regard to healthcare expenditure variables, we performed both a t-test and a Wilcoxon rank sum test and found statistically significant differences at the $0.1 \%$ level for both tests.

Next, we report three lifestyle risk factors for high-cost patients: BMI, pack-years smoked and physical activity. Consistent with the result in Leigh $e t$ al, high-cost patients have higher BMIs (24.32 vs 24.02), smoke more (8.31 vs 7.82 ) and exercise less ( 1.34 days vs 1.47 days).$^{20}$

We report the average count of chronic diseases for high-cost patients in table 1 . On average, high-cost patients have 4.87 chronic conditions while those in the non-high-cost group have 2.26. For example, more than half of our high-cost patients suffer from chronic lower back pain. Another common chronic disease for high-cost patients in our sample is hypertension. Approximately
$39 \%$ of high-cost patients have hypertension, while $26 \%$ in the non-high-cost group suffer from the same disease. The prevalence of cancer is much higher among highcost patients than among non-high-cost patients $(22.04 \%$ vs $3.03 \%$ ). Chronic ischaemic heart disease is another chronic disease with a large disparity: $15.16 \%$ for highcost patients versus $3.23 \%$ for the non-high-cost group.

While this disparity of chronic disease conditions has been reported in numerous prior studies of high-cost patients, the oral health characteristics of high-cost patients have not been reported. ${ }^{3}$ Table 2 presents the oral health condition, oral health behaviours and the three aforementioned self-reported oral symptoms.

First, we report the prevalence of periodontal diseases for the high-cost patients in table 2. We use the ICD-10 code (K05) from the claims data to identify those who were treated for periodontal diseases. The prevalence of periodontal diseases is higher in the high-cost patient group than in the non-high-cost group (28.6\% vs $25.9 \%$ ). The first oral health behaviour variable is the frequency of toothbrushing per day. Higher proportions of highcost patients report one time or less per day or two times per day, while a higher proportion of the non-high-cost group reports three times or more per day. The second oral health behaviour is the use of floss or/and interdental brushes. Again, high-cost patients use secondary oral products less: $5.64 \%$ for the high-cost patient group and $7.2 \%$ for the non-high-cost group.

We report three self-reported oral symptoms. Highcost patients are more likely to report tongue or insidecheek pain: $7.45 \%$ for the high-cost patient group and $6.40 \%$ for the non-high-cost group. The second symptom

\begin{tabular}{|c|c|c|c|}
\hline Patient characteristics & Non high cost & High cost & P value* \\
\hline \multicolumn{4}{|l|}{ Oral condition (\%) } \\
\hline Periodontal disease & $25.89(0.12)$ & $28.62(0.49)$ & $<0.0001$ \\
\hline \multicolumn{4}{|l|}{ Oral health behaviour (\%) } \\
\hline Frequency of toothbrushing & & & $<0.0001$ \\
\hline$\leq 1$ time per day & $8.26(0.08)$ & $10.95(0.34)$ & \\
\hline 2 times per day & $42.27(0.14)$ & $45.45(0.54)$ & \\
\hline$\geq 3$ times per day & $49.48(0.14)$ & $43.6(0.54)$ & \\
\hline Use of floss/interdental brush & $7.2(0.1)$ & $5.64(0.1)$ & $<0.0001$ \\
\hline \multicolumn{4}{|l|}{ Self-reported oral symptom (\%) } \\
\hline Tongue or inside-cheek pain & $6.40(0.07)$ & $7.45(0.22)$ & $<0.0001$ \\
\hline Difficulty in enunciation due to teeth/denture/gum conditions & & & $<0.0001$ \\
\hline Yes & $5.45(0.07)$ & $8.49(0.31)$ & \\
\hline Slightly & $46.47(0.14)$ & $48.69(0.55)$ & \\
\hline No & $48.08(0.14)$ & $42.82(0.54)$ & \\
\hline Difficulty in chewing food due to teeth/denture/gum conditions & $16.57(0.11)$ & $22.00(0.45)$ & $<0.0001$ \\
\hline
\end{tabular}

Values are presented as percentages with SE in parentheses.

${ }^{*} \mathrm{P}$ values are obtained by $\chi^{2}$ test. 
Table 3 ORs for future high-cost patients

\begin{tabular}{|c|c|c|c|c|c|}
\hline \multirow[b]{2}{*}{ Patient characteristics } & \multirow{2}{*}{$\begin{array}{l}\text { Univariate OR } \\
(95 \% \mathrm{Cl})\end{array}$} & Model 1† & Model 2‡ & Model 3§ & Model 4ף \\
\hline & & Multivariate OR & Multivariate OR & Multivariate OR & Multivariate OR \\
\hline \multicolumn{6}{|l|}{ Oral condition } \\
\hline \multicolumn{6}{|l|}{ Oral health behaviour } \\
\hline \multicolumn{6}{|l|}{$\begin{array}{l}\text { Toothbrushing (times/ } \\
\text { day) }\end{array}$} \\
\hline 2 & $1.22(1.17 \text { to } 1.27)^{\star \star \star}$ & $1.07(1.02-1.12)^{\star \star}$ & $1.04(0.99-1.08)$ & $1.05(1.00-1.10)^{\star}$ & $1.04(0.99-1.10)$ \\
\hline$\geq 3$ & Reference & & & & \\
\hline $\begin{array}{l}\text { Use of floss/ } \\
\text { interdental brush }\end{array}$ & $1.29(1.23 \text { to } 1.34)^{\star \star \star}$ & $1.07(1.03-1.12)^{\star \star}$ & $1.05(1.01-1.1)^{\star}$ & $1.08(1.04-1.14)^{\star \star}$ & $1.06(1.01-1.12)^{\star \star}$ \\
\hline \multicolumn{6}{|l|}{$\begin{array}{l}\text { Self-reported oral } \\
\text { symptom }\end{array}$} \\
\hline \multicolumn{6}{|l|}{$\begin{array}{l}\text { Difficult in enunciation } \\
\text { due to teeth/denture/ } \\
\text { gum conditions }\end{array}$} \\
\hline Yes & $1.74(1.61 \text { to } 1.89)^{\star \star \star}$ & $1.30(1.20-1.41)^{\star \star \star}$ & $1.09(1.04-1.14)^{\star \star}$ & $1.21(1.11-1.32)^{\star \star \star}$ & $1.15(1.05-1.26)^{\star *}$ \\
\hline Slightly & $1.23(1.18 \text { to } 1.28)^{\star \star \star}$ & $1.10(1.05-1.15)^{\star \star *}$ & $1.27(1.17-1.38)^{\star \star \star}$ & $1.08(1.03-1.13)^{\star \star \star}$ & $1.08(1.03-1.13)^{\star *}$ \\
\hline No & Reference & & & & \\
\hline $\begin{array}{l}\text { Difficult in chewing } \\
\text { food due to teeth/ } \\
\text { denture/gum } \\
\text { conditions }\end{array}$ & $1.34(1.28 \text { to } 1.41)^{\star \star \star}$ & $1.12(1.07-1.19)^{\star \star \star}$ & $1.11(1.05-1.17)^{\star \star}$ & $1.09(1.03-1.16)^{\star *}$ & $1.06(1.00-1.12)^{*}$ \\
\hline
\end{tabular}

Data are OR $(95 \% \mathrm{Cl})$.

${ }^{*} \mathrm{p}<0.05 ;{ }^{* *} \mathrm{p}<0.01 ;{ }^{* \star *} \mathrm{p}<0.001$.

†Adjustment for age, gender and income.

$\ddagger$ Adjustment for age, gender, income and lifestyle risk factors (BMI, pack-years smoked and physical activity).

$\S$ Adjustment for age, gender, income and chronic disease.

ๆAdjustment for age, gender, income, chronic disease, prior total healthcare cost and length of stay.

is difficulty in enunciation due to teeth/denture/gum conditions. A higher proportion of high-cost patients report this symptom compared with those in the non-highcost group: $8.49 \%$ of high-cost patients reported this symptom, while $5.45 \%$ of the non-high-cost group did so. The third symptom is difficulty in chewing food due to teeth/denture/gum conditions, with $22 \%$ of the highcost patient group reporting this symptom and $16.57 \%$ of the non-high-cost group doing so.

Table 3 presents the result of the binominal logistic regression analyses. Poor oral health measures are associated with a higher likelihood of a person becoming a high-cost patient in the subsequent year. The univariate ORs for all of the oral health measures are significant at the $0.1 \%$ level. Even after we adjust for age, gender and income level in the first model, all oral health measures have ORs greater than one, showing that poor oral health increases the odds of becoming a high-cost patient in the following year. In the second model, where we additionally adjust for the three lifestyle risk factors of BMI, pack-years smoked and physical activity, the ORs for oral health behaviour become less significant. The OR of the frequency of toothbrushing becomes statistically insignificant and the OR for the use of floss or interdental brushes becomes less significant in the second model. However, the OR for the prevalence of periodontal disease $(\mathrm{OR}=1.11 \%$ and $95 \% \mathrm{CI} 1.06$ to 1.16$)$ and those for the self-reported symptoms remain statistically significant in the second model.

To adjust for a high prevalence of multiple chronic conditions in high-cost patients, we adjust for chronic conditions in our third model. When chronic disease variables are introduced in the model, the OR for periodontal disease becomes statistically insignificant. To our final model, we add prior total healthcare cost and LOS, as they are powerful predictors of future high-cost patients. ${ }^{1}$ The ORs for the variables of use of floss or interdental brushes, tongue or inside-cheek pain and difficulty in enunciation are significant at the $1 \%$ level.

\section{DISCUSSION}

In the present study, we show a positive association between poor oral health and high-cost patient status. High-cost patients have a higher prevalence of periodontal diseases $(28.6 \%$ vs $25.9 \%)$. They are more likely 
to brush their teeth less than three times a day and are less likely to use floss or interdental brushes than the non-high-cost group. This positive association can partly be explained by prior studies that show positive associations between periodontal disease and various chronic and severe diseases. ${ }^{8-10}$ Other studies also find that the frequency of toothbrushing and the use of secondary oral hygiene products are associated with diseases such as hypertension, diabetes mellitus, cardiovascular disease, and head and neck cancers. ${ }^{11-14}$ In a recent study, researchers found that flossing and brushing of interdental spaces may reduce the risk for new cardiovascular events among patients with coronary heart disease. ${ }^{24}$ Moreover, our results show that the high-cost patient group is more likely to report tongue or inside-cheek pain $(7.45 \%$ vs $6.40 \%)$, difficulty in enunciation due to teeth/ denture/gum conditions and difficulty in chewing food due to teeth/denture/gum conditions (22\% vs $16.57 \%$ ) as compared with the non-high-cost group.

The prevalence of periodontal diseases shows a positive association with future high-cost patient status. However, when we adjust for chronic conditions, the statistical significance of the OR disappears. The associations between the oral health behaviour variables and future high-cost status are also statistically significant. However, the associations become less statistically significant when lifestyle risk factors are introduced in the model. This is due to the association between oral health behaviours and lifestyle risk factors, and the result is consistent with those in prior studies. ${ }^{625}{ }^{26} \mathrm{Kim}$ et al show that an increased frequency of toothbrushing and the number of secondary oral products used are associated with a lower BMI, less smoking and a higher level of physical activity. ${ }^{6}$

The associations between self-reported oral symptoms and future high-cost patient status remain statistically significant even after we adjust for demographic and socioeconomic measures, lifestyle risk behaviours, chronic diseases, and prior healthcare costs and utilisation rates. This shows that self-reported oral symptoms are a potential new source of data for high-cost prediction modelling.

\section{Strengths and limitation}

To the best of our knowledge, this is the first study to focus on the oral health of high-cost patients. Prior studies of high-cost patients and healthcare cost predictions indicate a high prevalence of multiple (chronic) conditions and lifestyle risk factors. ${ }^{320}$ However, the oral health characteristics of high-cost patients have not been studied. Our study fills this void in the literature using a large sample of 131549 enrollees. This study, however, does not explain or imply a causal relationship between oral health and the likelihood of becoming a high-cost patient. As Griffin et al point out, oral diseases can have an impact on many aspects of general health, and health conditions can in turn have an impact on oral health. ${ }^{27}$ Another limitation of this study is that we do not consider the longterm effects of oral health on healthcare expenditures.
However, 1-year prediction model is the most common study design in high-cost patient prediction literature. ${ }^{3}$

\section{Policy and research implications}

There are several implications pertaining to our work. Wammes et al argue that high-cost patients make up the sickest and most complex populations. ${ }^{3}$ They are a small portion of the population yet use the majority of healthcare resources. Accurately identifying high-cost patients and managing their care is a significant first step in improving quality levels and reducing population health costs. ${ }^{1}$ Actively exploring data sources available for their identification and prediction is a requisite for achieving these goals. To this end, our analysis provides a new data source for high-cost prediction modelling. Moreover, we have shown that people with poor oral health are at an increased risk of becoming high-cost patients. In that oral and other chronic and severe diseases also share common risk factors, it is important to examine the interplay between these diseases and oral disease as well as their combined impact when health policymakers develop programme involving targeted interventions for high-cost patients and develop preventive measures at the population level. ${ }^{27}$

In conclusion, we demonstrate that oral health measures are associated with the risk of becoming a highcost patient. Our results highlight the impact of oral health on healthcare costs and support the development of preventive measures at the population level.

Acknowledgements I would like to thank Ms Boram Park and Ms Kyung-Ran Lee at the NHIS for providing answers to numerous questions on the NHIS medical check-up database used in this study.

Contributors YJK conceptualised and designed the study, collected and analysed the data, and wrote the manuscript.

Funding The authors have not declared a specific grant for this research from any funding agency in the public, commercial or not-for-profit sectors.

Competing interests None declared.

Patient consent for publication Not required.

Ethics approval The Seoul National University Institutional Review Board.

Provenance and peer review Not commissioned; externally peer reviewed.

Data availability statement Data may be obtained from a third party and are not publicly available.

Open access This is an open access article distributed in accordance with the Creative Commons Attribution Non Commercial (CC BY-NC 4.0) license, which permits others to distribute, remix, adapt, build upon this work non-commercially, and license their derivative works on different terms, provided the original work is properly cited, appropriate credit is given, any changes made indicated, and the use is non-commercial. See: http://creativecommons.org/licenses/by-nc/4.0/.

\section{REFERENCES}

1. Tamang S, Milstein A, Sørensen HT, et al. Predicting patient 'cost blooms' in Denmark: a longitudinal population-based study. BMJ Open 2017;7:e011580.

2. Naessens JM, Baird MA, Van Houten HK. Predicting persistently high primary care use. Ann Fam Med 2005;3:324-30.

3. Wammes JJG, van der Wees PJ, Tanke MAC, et al. Systematic review of high-cost patients' characteristics and healthcare utilisation. BMJ Open 2018;8:e023113.

4. Adolph M, Darnaud C, Thomas F, et al. Oral health in relation to allcause mortality: the IPC cohort study. Sci Rep 2016;2017:3-8. 
5. Sabbah W, Mortensen LH, Sheiham A, et al. Oral health as a risk factor for mortality in middle-aged men: the role of socioeconomic position and health behaviours. J Epidemiol Community Health 2013;67:392-7.

6. Kim Y-H, Kim D-H, Lim KS, et al. Oral health behaviors and metabolic syndrome: the 2008-2010 Korean National health and nutrition examination survey. Clin Oral Investig 2014:18:1517-24.

7. Joshy G, Arora M, Korda RJ, et al. Is poor oral health a risk marker for incident cardiovascular disease hospitalisation and all-cause mortality? Findings from 172630 participants from the prospective 45 and Up Study. BMJ Open 2016;6:e012386.

8. Galgut PN. Periodontal disease and poor health outcomes. BMJ 2010;340:c2735

9. Lee J-H, Kweon HH-I, Choi J-K, et al. Association between periodontal disease and prostate cancer: results of a 12year longitudinal cohort study in South Korea. J Cancer 2017;8:2959-65.

10. Gaur S, Agnihotri R. Alzheimer's disease and chronic periodontitis: is there an association? Geriatr Gerontol Int 2015;15:391-404.

11. Kuwabara M, Motoki Y, Ichiura K, et al. Association between toothbrushing and risk factors for cardiovascular disease: a largescale, cross-sectional Japanese study. BMJ Open 2016;6:e009870.

12. de Oliveira C, Watt R, Hamer M. Toothbrushing, inflammation, and risk of cardiovascular disease: results from Scottish health survey. BMJ 2010;340:c2451.

13. Farquhar DR, Divaris K, Mazul AL, et al. Poor oral health affects survival in head and neck cancer. Oral Oncol 2017;73:111-7.

14. Darnaud C, Thomas F, Pannier B, et al. Oral health and blood pressure: the IPC cohort. Am J Hypertens 2015;28:1257-61.

15. Kim JK, Baker LA, Davarian S, et al. Oral health problems and mortality. Journal of Dental Sciences 2013;8:115-20.

16. Seong SC, Kim Y-Y, Park SK, et al. Cohort profile: the National health insurance Service-National health screening cohort (NHIS-HEALS) in Korea. BMJ Open 2017;7:e016640.
17. Lee J, Lee JS, Park S-H, et al. Cohort profile: the National health insurance Service-National sample cohort (NHIS-NSC), South Korea. Int J Epidemiol 2016;95:dyv319.

18. Kim HB, Lee SA, Lim W. Knowing is not half the battle: impacts of information from the National health screening program in Korea. IZA Discuss Pap 2017.

19. Kim ST, Seong SC. National Health Insurance Statistical Yearbook. Seoul: Health Insurance Review \& Assessment Service, National Health Insurance Service, 2015.

20. Leigh J, Hubert $\mathrm{H}$, Romano P. Lifestyle risk factors predict healthcare costs in an aging cohort. Am J Prev Med 2005;29:379-87.

21. Fleishman JA, Cohen JW. Using information on clinical conditions to predict high-cost patients. Health Serv Res 2010;45:532-52.

22. Leininger LJ, Friedsam D, Voskuil K, et al. Predicting highneed cases among new Medicaid enrollees. Am J Manag Care 2014;20:e399-407 http://www.ncbi.nlm.nih.gov/pubmed/25364876

23. van den Bussche $\mathrm{H}$, Koller $\mathrm{D}$, Kolonko $\mathrm{T}$, et al. Which chronic diseases and disease combinations are specific to multimorbidity in the elderly? results of a claims data based cross-sectional study in Germany. BMC Public Health 2011;11:101.

24. Reichert S, Schlitt A, Beschow V, et al. Use of floss/interdental brushes is associated with lower risk for new cardiovascular events among patients with coronary heart disease. J Periodontal Res 2015;50:180-8.

25. Tada A, Matsukubo T. Relationship between oral health behaviors and general health behaviors in a Japanese adult population. $J$ Public Health Dent 2003;63:250-4.

26. Kim H-J, Kim Y-H, Cho K-H, et al. Oral health behaviors and bone mineral density in South Korea: the 2008-2010 Korean National health and nutrition examination survey. $J$ Bone Miner Metab 2016;34:225-33.

27. Griffin SO, Jones JA, Brunson D, et al. Burden of oral disease among older adults and implications for public health priorities. Am J Public Health 2012;102:411-8. 